\section{Penetrating eye injuries in South African children: aetiology and visual outcome}

\begin{abstract}
Purpose To assess the aetiology, prognosis, and visual outcome of penetrating eye injuries in South African children.

Methods In all, 100 consecutive patients, aged 16 years and under, with penetrating ocular injuries undergoing surgery between January 2001 and November 2002 were prospectively evaluated.

Results Most children (66\%) were injured during play. In all, $55 \%$ of penetrating eye injuries occurred at home, and all injuries to children under the age of 6 years occurred there. Most injuries occurred in the absence of a caregiver (85\%). Sticks, wire, and glass caused half of all injuries $(48 \%)$. The most common mechanism of injury was impact with a sharp object $(46 \%)$. Only $25 \%$ of injured presented to the hospital within $24 \mathrm{~h}$ of injury; the more severe the sustained injury and the younger the patient, the earlier was attendance at the clinic. Most patients $(71 \%)$ regained best-corrected visual acuity (Snellen equivalent) of 20/200 or better, and $51 \%$ regained $20 / 40$ or better. Patient age and delay of presentation were not of prognostic value. Indicators of poor visual outcome were identified as wound size greater than $11 \mathrm{~mm}$ in length, mixed corneoscleral type wounding, and involvement of the lens and posterior segment in the injury.

Conclusions Penetrating eye injuries in African children, reviewed here, generally occur when children are at play in a domestic setting. Effective prevention should stress parental awareness, careful supervision, greater home safety, safe toys, and avoidance of hazardous games.
\end{abstract}

Eye (2006) 20, 789-795. doi:10.1038/sj.eye.6702003; published online 1 July 2005

MC Grieshaber ${ }^{1,2}$ and R Stegmann ${ }^{1}$

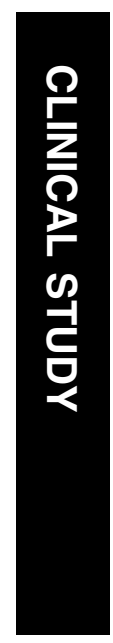

Keywords: penetrating eye injury; children; aetiology; trauma

\section{Introduction}

Penetrating eye injuries are a leading cause of unilateral noncongenital visual loss. Children account for up to $50 \%$ of all ocular trauma, ${ }^{1-7}$ thus representing the highest incidence. The incidence pattern of penetrating eye injuries in children living in African rural areas is likely to differ from that of adults, of children from metropolitan areas, and from that of children from developed countries; it thus merits closer examination. Whereas most penetrating ocular injuries in adults seem to be preventable with existing protective devices, those in children are often unforeseen, and situations of potentially greater risk are less predictable. Identifying underlying aetiological factors may allow us to take effective preventative measures to reduce the incidence of such injuries in children. Epidemiological data pertaining to childhood penetrating eye injuries in developed countries have been published, ${ }^{8-11}$ but there are few studies of the situation in Africa. ${ }^{12-14}$ In South Africa, no current data are available with which accurately to assess the importance of ocular trauma in children in terms of frequency, distribution, and impact on vision.

This study assesses the aetiological factors underlying penetrating ocular injuries in children, presented to a single tertiary referral care institution in South Africa serving a population of about 4 million. The visual outcomes of these injuries and prognostic factors are evaluated.
${ }^{1}$ Department of Ophthalmology, Medical University of Southern Africa, PO Box 66, Medunsa 0204,

South Africa

${ }^{2}$ University Eye Clinic Basel, Mittlere Strasse 91, PO Box CH-4012 Basel, Switzerland

Correspondence: MC Grieshaber, University Eye Clinic Basel, Mittlere Strasse 91, PO Box CH-4012 Basel, Switzerland E-mail: mgrieshaber@ uhbs.ch

Received: 16 November 2004

Accepted in revised form: 2 June 2005

Published online: 1 July 2005

Financial support: Neither public nor private financial support was received for this study.

Financial disclosure: None of the authors has any financial or proprietary interest in any material or method mentioned. 


\section{Materials and methods}

A total of 100 consecutive full-thickness penetrating eye injuries in children, aged 16 years or younger, presenting to the Department of Ophthalmology, Medical University of Southern Africa (Medunsa), from January 2001 to November 2002, were prospectively investigated. A detailed history focusing on circumstances of the trauma was obtained from parents or caretakers or each child according to a standardised form; this was followed by complete ophthalmic examination. Children were only included if there was clear evidence of recent, full-thickness penetration at the time of initial examination (often under anaesthesia) or primary surgical repair. Former full-thickness lacerations, either naturally healed or repaired at other institutions, as well as partial thickness lacerations were excluded. Penetrating eye injuries were defined according to the Birmingham Eye Trauma Terminology system of Kuhn et al. ${ }^{15}$ The location and severity of the injury were assessed pursuant to the Ocular Trauma Classification Group guidelines. ${ }^{16}$ In addition, we distinguished between central and peripheral corneal lacerations as we have previously observed a difference in terms of the visual outcome (personal experience).

Particular attention was paid to the case history to determine the cause, mechanism, locale of occurrence, and time of trauma occurrence, and to the initial examination to record the type, size, location, and severity of the wound. We further investigated whether these factors were associated with a favourable or unfavourable outcome. Early complications were defined as those found on initial examination; all other complications were referred to as late complications. Surgery was performed under general anaesthesia. After exploring the extent of the wounds, corneal lacerations were sutured with 11-0 nylon sutures and scleral lacerations with 7-0 vicryl sutures. The lens was removed if lens damage was present, but no intraocular lens (IOL) was implanted at the time of wound repair. Prolapsed uveal tissue or vitreous was reduced or excised. Second surgeries, such as vitrectomy, lens aspiration, or IOL implantation, were performed later, if needed. Visual acuity before surgery was measured whenever possible with reference to the patient's age and collaboration during the examination. Final visual acuity was defined as the most recently recorded, best-corrected visual acuity (Snellen equivalent) of patients either discharged from follow-up or absent from further examinations for more than 6 months. Children were classified in three age groups: preschool age, $0-5$ years; primary school age, 6-10 years; and secondary school age, 11-16 years.

\section{Statistical methods}

We performed data analysis using SPSS software, version 11.0 (SPSS Inc., Chicago, IL, USA), using frequency tables to describe categorical variables and descriptive statistics to determine continuous variables (demographic data). To evaluate the association between final visual acuity, age group, and categorical variables (eg causative agent, mechanism of injury, activity, and place), the Fisher's exact test was used, being considered statistically significant when two-sided $P$-values $<0.05$. To evaluate the relationship between ordinate variables, the Spearman rank-correlation analysis (coefficient $\rho$ ) was employed. The level of significance was set at $5 \%$.

\section{Results}

\section{Age and gender distribution of patients}

The mean age of our patients was 9.4 years age (range, 8 months to 15 years 9 months). The age and sex distribution is presented in Figure 1, which shows one peak between the ages of 8 and 10 years and another at the age of 16 years. In all, 70 of the 100 patients were male, for an average male: female ratio of $2.3: 1$, this being significant at $P<0.001$. The highest male: female ratio of penetrating trauma was found in the 6- to 10-year-old age group, with a frequency of $3.3: 1$ boys with eye injuries for every girl. The youngest group (0-5 years) showed a considerably lower ratio of $1.7: 1$. The right eye was involved in 57 and the left eye in 43 patients. At first presentation, it was possible to determine the visual acuity of 92 children; 62 of these (67.4\%) had less than 20/200 vision, including seven children with no light perception (LP).

\section{Agents, place, and activity}

The causative agents were divided into groups where five or more similar causes were identified. Sticks, wire, and glass account for half of all causative objects (48\%), but taken individually none was statistically significant. Injuries from sticks frequently occurred when children played a game where one opponent has to hit another on the back to gain points. Less common were stick injuries sustained from sports activities such as relay racing, or from domestic activities involving fetching or chopping firewood. A typical injury caused by a wire might occur when a child was forming his own toy out of a metal wire.

Thorns, stones, and pens caused no injuries in children under the age of 6 years. Agents such as a thrown fruit core, falling mirror, razorblade, nail, arrow, cricket bat, or dog-bite were rare. The mean age of patients injured with 


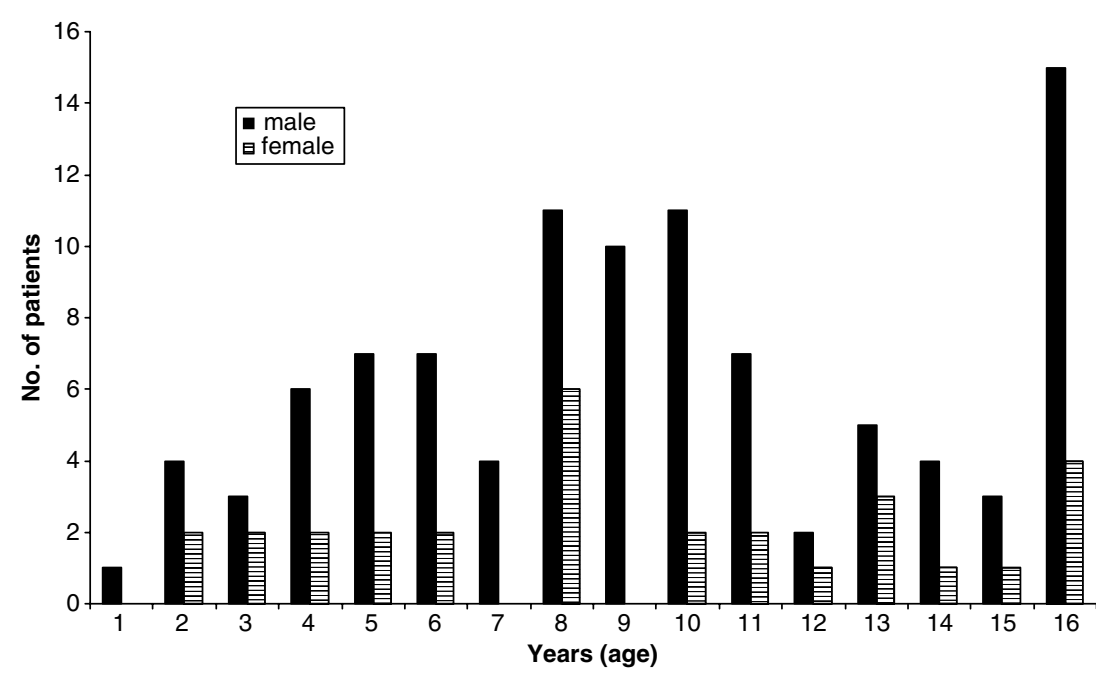

Figure 1 Age and gender distribution.

thorns was 12.6 years, whereas those injured by wires were younger, with a mean age of 8.4 years.

The most common mechanism of injury was by getting hit by a sharp object (46\%). Under the age of 6 years, children frequently became injured while observing parents at domestic work. In all, 33\% of all injuries were self-inflicted by the patient, females under the age of 11 years being involved twice as frequently as males $(2.2: 1)$ in such injuries. A total of 66 children were injured during play. Adults were actively involved in only five injuries, all occurring in children under the age of 6 years $(P<0.001)$.

The great majority of injuries occurred in the absence of a caregiver (85\%). Distribution by age group showed that $95.3 \%$ of children aged $6-10$ years, $91.6 \%$ aged $11-16$ years, and $47.6 \%$ aged $0-5$ years were alone or without adult supervision at the time of the eye injury $(P<0.001)$. In terms of place, the home (55\%) was the most common place for penetrating eye injuries to occur; moreover, all injuries of children under the age of 6 years happened at home $(P=0.005)$. Six children sustained injuries while at school, all but one of these injuries happening accidentally with pen tips. Road traffic accident was an infrequent cause.

\section{Time of injury occurrence}

The time of injury occurrence was grouped into three periods: morning (0600-1200 h), afternoon (1200-1800 h), and evening (1800-2400 h). No injuries occurred from 2400 to $0600 \mathrm{~h}$. The majority of injuries occurred in the afternoon (72 patients), this result being highly significant $(P<0.001)$. Seasonal peaks were seen in winter and spring (34 and 31 patients, respectively), while penetrating eye injuries were less common in summer and fall (17 and 18 patients, respectively) $(P=0.006)$. Of the 79 children attending school, 26 sustained injury during school holidays and 12 on weekends during school holidays, which was not significant $(P=0.89)$. There was no relationship between injury occurrence and moon phases.

\section{Time interval between injury and presentation at Medunsa}

The time interval between injury and presentation at the eye clinic is shown in Table 1 . Only 25 patients presented within $24 \mathrm{~h}$ of injury; within $48 \mathrm{~h}$, however, 62 patients presented injury. There was a trend towards early attendance, within $48 \mathrm{~h}$, the more severe the injury and the younger the child ( $\rho=-0.179 ; P=0.07)$. In all, 20 of 21 children $(95.2 \%)$ aged 6 years and younger, and 26 of 43 children $(60.5 \%)$ aged 6-10 years came to the hospital within $48 \mathrm{~h}$ of injury. However, only 16 of 36 children $(44.4 \%)$ aged 11 years and older sought medical assistance in the same period $(P<0.001)$.

\section{Visual outcome}

For the present study, visual acuity was classified as category $1(20 / 20-20 / 40)$, category $2(20 / 50-20 / 200)$, category $3(<20 / 200-$ LP), and category 4 (no light perception: NLP). At initial examination, it was possible to obtain the visual acuity in 92 children: 62 of these $(67.4 \%)$ had less than 20/200 vision, including seven children with NLP. The final visual outcomes were overall good (Table 2): 71 patients showed a visual acuity of $20 / 200$ or better and 51 of even $20 / 40$ or better. Of the 
Table 1 Interval between injury and presentation at Medunsa $\varphi$

\begin{tabular}{|c|c|c|c|c|c|c|}
\hline & $<24 h$ & $24-48 h$ & $2-6$ days & 1 week & 2-4 weeks & Total no. \\
\hline Wound (W) only & 1 & 3 & 5 & 2 & - & 11 \\
\hline $\mathrm{W}+$ iris prolapse & 6 & 9 & 3 & - & 2 & 19 \\
\hline$W+$ lens & 7 & 8 & 7 & 4 & 6 & 32 \\
\hline $\mathrm{W}+$ iris prolapse + lens & 4 & 6 & 2 & - & - & 12 \\
\hline$W+$ posterior segment & - & 3 & - & - & - & 3 \\
\hline $\mathrm{W}+$ lens + posterior segment & 7 & 8 & 7 & - & - & 22 \\
\hline
\end{tabular}

$\varphi$ Spearman rank correlation: $P=0.07$.

Table 2 Final visual acuity in relation to delay of attendance, patient age, location and size of wound, and nature of injury

\begin{tabular}{|c|c|c|c|c|c|c|c|}
\hline & $20 / 20-20 / 40$ & $20 / 50-20 / 200$ & $<20 / 200-L P$ & $N L P$ & $N A$ & Total no. & Spearman (P-value) \\
\hline Delay of attendance & & & & & & & 0.59 \\
\hline Same day & 14 & 5 & 3 & 3 & - & 25 & \\
\hline 1 day & 19 & 6 & 5 & 6 & 2 & 38 & \\
\hline 2-6 days & 10 & 5 & 2 & 5 & 1 & 23 & \\
\hline 1-2 weeks & 4 & 3 & - & 1 & - & 8 & \\
\hline 2-4 weeks & 4 & 1 & 1 & - & - & 6 & \\
\hline Patient age (years) & & & & & & & 0.42 \\
\hline $0-6$ & 10 & 3 & 2 & 5 & 1 & 21 & \\
\hline $6-11$ & 19 & 13 & 6 & 3 & 2 & 43 & \\
\hline $11-16$ & 22 & 4 & 3 & 7 & - & 36 & \\
\hline Location of wound ${ }^{\text {a }}$ & & & & & & & 0.001 \\
\hline Zone 0 & 8 & 12 & 3 & - & 2 & 25 & \\
\hline Zone I & 34 & 5 & 6 & 5 & - & 50 & \\
\hline Zone II & 6 & 3 & 2 & 10 & 1 & 22 & \\
\hline Zone III & 3 & - & - & - & - & 3 & \\
\hline Size of wound (mm) & & & & & & & $<0.001$ \\
\hline $0-5$ & 34 & 12 & 6 & 2 & 2 & 51 & \\
\hline $6-10$ & 16 & 7 & 2 & 2 & 1 & 28 & \\
\hline $11-15$ & 1 & 1 & 3 & 8 & - & 13 & \\
\hline$>15$ & - & - & - & 3 & - & 3 & \\
\hline Severity of injury & & & & & & & $<0.001$ \\
\hline Wound (W) only & 8 & 1 & 1 & 1 & - & 11 & \\
\hline $\mathrm{W}+$ iris prolapse & 18 & 1 & - & - & - & 19 & \\
\hline $\mathrm{W}+$ lens & 13 & 14 & 3 & - & 3 & 33 & \\
\hline $\mathrm{W}+$ iris prolapse + lens & 7 & 2 & 2 & 1 & - & 12 & \\
\hline $\mathrm{W}+$ posterior segment & 2 & - & 1 & - & - & 3 & \\
\hline $\mathrm{W}+$ lens + posterior segment & 3 & 2 & 4 & 13 & - & 22 & \\
\hline Total patients & 51 & 20 & 11 & 15 & 3 & 100 & \\
\hline
\end{tabular}

aThe most posterior location; I-III: based on the classification of the Ocular Trauma Classification Group; in addition, zone 0 represents cornea centre. $\mathrm{LP}=$ light perception; $\mathrm{NLP}=$ no light perception; $\mathrm{NA}=$ not available.

males, $57.7 \%$ attained a final visual acuity of $20 / 40$ or better compared to $34.5 \%$ of the females. Penetrating ocular injuries caused by small-sized agents such as thorns, wire, pens, and pieces of glass had been assumed to have a better visual outcome; but in fact, the size of causative agent did not prove to be a significant prognostic factor. The interval between occurrence of injury and presentation at the eye clinic was not of prognostic value for visual outcome either: 17 of 63 patients $(26.9 \%)$ seen within $48 \mathrm{~h}$ achieved a final visual acuity of less than 20/200, while eight of 14 the patients $(57.1 \%)$ seen 1 week or more after the injury occurred 
achieved a final visual acuity of $20 / 40$ or better. When visual outcome was compared to patient' age, there was an almost equal percentage of visual acuity of $20 / 40$ or better in all three groups $(\rho=-0.83 ; P=0.4)$.

Final visual acuity was compared to the location, size, and severity of injury (Table 2). Mixed corneoscleral (zone II) wounds were strongly associated with unfavourable outcomes, mainly due to phthisis bulbi. Purely scleral (zone III) and peripheral corneal lacerations (zone I) offered a better prognosis ( $\rho=0.32$; $P=0.001)$. The size of the wound was found to be a significant prognostic indicator $(\rho=0.36 ; P<0.001)$. In all, 51 children had a globe laceration of $5 \mathrm{~mm}$ in length or less: 34 of these $(66.7 \%)$ recovered to vision of $20 / 40$ or better. Only five of 13 patients with lacerations of $11-15 \mathrm{~mm}$ in length recovered to LP or better.

Considering the severity of the penetrating injuries, the presence of lens involvement was associated with poorer outcome. Of $30(86.7 \%)$ children, 26 with anterior globe laceration with or without iris prolapse showed a visual acuity of $20 / 40$ or better compared to 20 children with additional lens trauma (44.4\%). As expected, in accordance with the severity of the injury, severe visual impairment and blindness were caused by the presence of retinal detachment and vitreous prolapse. Comprised here as posterior segment involvement, the predicted visual outcome was less positive $(\rho=0.54 ; P<0.001)$.

Other complicating factors, such as haemorrhage and infection, also contributed to poor outcome. Of 13 patients, 10 with hyphaema at initial examination showed a retinal detachment in the B-scan.

Endophthalmitis was found in four patients. All of these patients had delayed presentation for 5 or more days after injury occurrence and had sustained injury from the thorns of bushes; the visual outcome was unfavourable in all eyes with NLP before surgery. Pupillary block in two and angle recession glaucoma in three patients were rare in penetrating eye injuries in this series. In contrast, late complications (21 patients) were more frequent and associated with poor visual outcome $(<20 / 200)$. Eight of 10 patients with phthisis bulbi were found at first examination to be suffering from hyphaema and retinal detachment, while seven showed corneoscleral laceration. Amblyopia was associated with either anisometropic astigmatism or corneal scarring in all patients. Three patients suffered from macular atrophy.

\section{Discussion}

The male preponderance is a common feature of eye injuries in children. The male-to-female ratio $(2: 1)$ in this study is one of the lowest reported in the literature. ${ }^{12}$ In developed countries, the ratio is higher at between $4: 1^{4,5,17,18}$ and $5: 1{ }^{19}$ This difference may relate to differences in activities, age distribution, and socioeconomic status. Boys and girls in developing countries tend to engage in more similar, mainly outdoors activities; toys especially designed for either girls or boys are simply not affordable. Often materials from the natural environment, such as stones and pieces of wood, are used in playing. It was not unusual for small children to be playing within the reach of hazardous objects such as glass, needles, and wire, even when supervising adults - not instructed of the dangers of these objects - are present. In particular, small children were often allowed to observe adult activities, such as wood chopping, that could pose a risk to them. This suggests a general lack of awareness or even neglect with regard to the dangers that certain objects and activities represent for children.

Most of the children we studied who sustained penetrating ocular injuries were older than 6 years. The mean age of 9.4 years was similar to that found by previous studies of eye injuries in childhood. ${ }^{17,20}$ The frequency of injury increases with increasing activity as the child gets older. School-aged children, in particular, are more often exposed to the environment and tend to be more physically active. As well, they often take higher risks to gain acceptance from their peers. This is reflected in the types of games they play and how they react to conflictive situations.

The home environment was found to be the most common place of injury occurrence. In fact, all injuries among preschoolers occurred there, as these children spent most of their time at home. In contrast, only $6 \%$ of all injuries occurred at school, indicative of a higher level of safety there than in the home environment. The incidence of injuries caused by motor vehicle accident is at $1 \%$ very low in comparison with that found by other studies. ${ }^{9,11,20,21}$ This may be explained by little traffic in the predominantly rural areas we studied, and by the use of public transportation by most of the children.

Despite the knowledge that children, and infants in particular, should be supervised at all times, the present study found that the vast majority of injuries (85\%) occurred while children were unattended. The absence of an adult is of great concern, and has been reported to occur mainly in lower socioeconomic strata. ${ }^{22}$ Most of the children we studied from underprivileged strata stayed with grandparents or older siblings during the daytime while parents were working. Adult supervision has been found to be of paramount importance in preventing accidents, ${ }^{22}$ so there is an enormous need for primary prevention programs targeting parents and caregivers in this African population. However, the lack of supervision is not restricted to developing countries as has already been pointed out in recent studies from the western world. $^{8-11}$ 
Visual outcome and prognosis is expected to improve with prompt medical examination and therapy. However, socioeconomic, geographic, and cultural factors may keep patients from receiving timely and appropriate medical assistance. More than $75 \%$ of the children examined in this study received eye care more than $24 \mathrm{~h}$ after injury. The delay between time of injury and attendance at the tertiary hospital was mainly referred to lack of recognition of the severity of the trauma either by parents or by inexperienced medical officers at primary health-care centres. This underscores the need for increased awareness and education to overcome this widespread negligence and ignorance. Other minor factors such as transportation and hospital expense, as well as the travelling time contributed to the delay.

Nonetheless, final visual outcomes were on the whole encouraging, as one in two children obtained a final visual acuity better than $20 / 40$. Interestingly, delay of attendance was not associated with an unfavourable outcome if no infection, which was rare, occurred. Poor initial visual acuity was not found to be a prognostic indicator of final visual outcome in this study, as long as LP was present; this is in contrast to the findings of previous studies of penetrating eye injuries. ${ }^{1,3,19}$ Several factors may account for this difference, including less accurate assessment of the initial visual acuity of an anxious child and the presence of a marked corneal oedema or traumatic cataract in children with a delay of initial presentation. The indicators of poor prognosis identified here are similar to those identified by other studies, ${ }^{19,23}$ comprising length of wound $>11 \mathrm{~mm}$, mixed corneoscleral wound location, and involvement of the lens and posterior segment. The size of the causative agents proved not to be a significant prognostic factor, as penetrating ocular injuries caused by small-sized agents, such as thorns and wire, did not have a significantly better visual outcome. Young children with sustained ocular injuries are more prone to developing amblyopia than older children. ${ }^{7,19,24}$ However, poor visual outcome was more correlated to the severity of the injury, rather than to patient age or to delay of attendance. It seems that younger children were involved in milder forms of injury.

The results of this study of penetrating eye injuries in African children emphasise that home and playground, at least in South Africa, are not safe places for children to play, that available games and toys are fraught with potential dangers, and that parental supervision is insufficient. As prevention is better than cure, parents need education in making the home environment safer for children. Thorny bushes near homes or playgrounds should be removed or fenced in. Increased and more careful adult supervision is of great value in preventing eye injuries in children, ${ }^{14,22,25}$ since they cannot be fully responsible for their actions. Access to sharp instruments, close observation of dangerous adult work, and potentially hazardous games with sticks or sharp missiles must be restricted. A difficult but desirable task would be introducing new, less dangerous games and supplying these underprivileged children with safe toys.

An efficient educational campaign should emphasise specific dangers and their avoidance, stress the potentially devastating effects of ocular injuries in childhood, and be addressed to parents, community workers, and teachers as well as to medical personnel in primary health-care centres.

\section{Acknowledgements}

We thank Andreas Schötzau, MS, for assistance with the statistics, and Günter Niemeyer, MD, for constructive comments on the manuscript.

\section{References}

1 Sternberg Jr P, de Juan Jr E, Michels RG. Penetrating ocular injuries in young patients. Initial injuries and visual results. Retina 1984; 4(1): 5-8.

2 Eagling EM. Perforating injuries of the eye. Br J Ophthalmol 1976; 60(11): 732-736.

3 De Juan Jr E, Sternberg Jr P, Michels RG. Penetrating ocular injuries. Types of injuries and visual results. Ophthalmology 1983; 90(11): 1318-1322.

4 Niiranen M, Raivio I. Eye injuries in children. $\mathrm{Br}$ J Ophthalmol 1981; 65(6): 436-438.

5 Patel BC. Penetrating eye injuries. Arch Dis Child 1989; 64(3): 317-320.

6 Spiegel D, Nasemann J, Nawrocki J, Gabel VP. Severe ocular trauma managed with primary pars plana vitrectomy and silicone oil. Retina 1997; 17(4): 275-285.

7 Jandeck C, Kellner U, Bornfeld N, Foerster MH. Open globe injuries in children. Graefes Arch Clin Exp Ophthalmol 2000; 238(5): 420-426.

8 Luff AJ, Hodgkins PR, Baxter RJ, Morrell AJ, Calder I. Aetiology of perforating eye injury. Arch Dis Child 1993; 68(5): 682-683.

9 Punnonen E. Epidemiological and social aspects of perforating eye injuries. Acta Ophthalmol (Copenhagen) 1989; 67(5): 492-498.

10 Alfaro DV, Chaudhry NA, Walonker AF, Runyan T, Saito Y, Liggett PE. Penetrating eye injuries in young children. Retina 1994; 14(3): 201-205.

11 Thompson CG, Kumar N, Billson FA, Martin F. The aetiology of perforating ocular injuries in children. $\mathrm{Br} J$ Ophthalmol 2002; 86(8): 920-922.

12 Umeh RE, Umeh OC. Causes and visual outcome of childhood eye injuries in Nigeria. Eye 1997; 11(Part 4): 489-495.

13 Olurin O. Eye injuries in Nigeria. A review of 433 cases. Am J Ophthalmol 1971; 72(1): 159-166.

14 Gordon YJ, Mokete M. Pediatric ocular injuries in Lesotho. Doc Ophthalmol 1982; 53(3): 283-289. 
15 Kuhn F, Morris R, Witherspoon CD, Heimann K, Jeffers JB, Treister G. A standardized classification of ocular trauma. Graefes Arch Clin Exp Ophthalmol 1996; 234(6): 399-403.

16 Pieramici DJ, Sternberg Jr P, Aaberg Sr TM, Bridges Jr WZ, Capone Jr A, Cardillo JA et al. A system for classifying mechanical injuries of the eye (globe). The Ocular Trauma Classification Group. Am J Ophthalmol 1997; 123(6): 820-831.

17 Baxter RJ, Hodgkins PR, Calder I, Morrell AJ, Vardy S, Elkington AR. Visual outcome of childhood anterior perforating eye injuries: prognostic indicators. Eye 1994; 8(Part 3): 349-352.

18 LaRoche GR, McIntyre L, Schertzer RM. Epidemiology of severe eye injuries in childhood. Ophthalmology 1988; 95(12): 1603-1607.

19 Farr AK, Hairston RJ, Humayun MU, Marsh MJ, Pieramici DJ, MacCumber MW et al. Open globe injuries in children: a retrospective analysis. J Pediatr Ophthalmol Strab 2001; 38(2): 72-77.
20 Rudd JC, Jaeger EA, Freitag SK, Jeffers JB. Traumatically ruptured globes in children. J Pediatr Ophthalmol Strab 1994; 31(5): 307-311.

21 Hall NF, Denning AM, Elkington AR, Cooper PJ. The eye and the seatbelt in Wessex. Br J Ophthalmol 1985; 69(5): 317-319.

22 Moreira Jr CA, Debert-Ribeiro M, Belfort Jr R. Epidemiological study of eye injuries in Brazilian children. Arch Ophthalmol 1988; 106(6): 781-784.

23 Elder MJ. Penetrating eye injuries in children of the West Bank and Gaza strip. Eye 1993; 7(Part 3): 429-432.

24 Sharma T, Agarwal P, Gopal L, Badrinath SS, Murugesan R. Penetrating ocular trauma in children by 'broomstick bows and arrows'. Ophthalmic Surg 1994; 25(3): 175-179.

25 Niiranen M. Perforating eye injuries: A comparative epidemiological, prognostic and socioeconomic study of patients treated in 1930-1939 and 1950-1959. Acta Ophthalmol 1978; 135(Suppl): 1-87. 